DOI: 10.12957/demetra.2017.25890

\title{
Qualidade nutricional de cardápios planejados para restaurantes universitários de universidades federais do Brasil
}

\author{
Nutrition quality of menus planned for restaurants university of universities federal of Brazil
}

\author{
Joyce Larissa da Silva Benvindo \\ Ana Maria de Souza Pinto² \\ Daniel Henrique Bandoni² \\ 1 Universidade Federal de São Paulo, Programa \\ de Pós-graduação em Alimentos, Nutrição e \\ Saúde. São José dos Campos-SP, Brasil. \\ ${ }^{2}$ Departamento de Saúde, Clínica e Instituições \\ da Universidade Federal de São Paulo, campus \\ Baixada Santista. São Paulo-SP, Brasil. \\ Correspondência / Correspondence \\ Joyce Larissa da Silva Benvindo \\ E-mail: joycelarissa20@gmail.com
}

\section{Resumo}

Objetivo: Avaliar a qualidade nutricional de cardápios planejados para os restaurantes universitários das Universidades Federais no Brasil. Material e Métodos: Estudo transversal quantitativo, com cardápios de 22 restaurantes universitários, divididos em suas respectivas regiões, e planejados para o almoço do mês de março de 2015. Para a análise, utilizou-se o método da Avaliação Qualitativa das Preparações do Cardápio - AQPC, o Guia Alimentar para a População Brasileira, e a publicação do Ministério da Saúde sobre Alimentos Regionais Brasileiros. Resultados e Discussão: Pelo AQPC, a presença de folhosos, carne gordurosa e conservas apresentaram-se adequadas nas cinco regiões. Já a monotonia das cores e alimentos ricos em enxofre tiveram percentuais inadequados, despertando um alerta, pois cardápios coloridos tornam-se mais atraentes visualmente e o consumo de refeições ricas em enxofre pode causar desconforto abdominal. A oferta de prato proteico vegetariano nas regiões Sul e Sudeste ocorreu em $50 \%$ e $88 \%$ dos cardápios analisados, respectivamente. E quanto à presença de arroz integral, 83\% dos cardápios da região Sul e $78 \%$ dos cardápios da região Sudeste planejaram a oferta. Vale ressaltar que o planejamento dos dois itens foi menos frequente ou não ofertado pelas regiões Centro-oeste, Norte e Nordeste. A maior parte dos restaurantes disponibiliza doces ultraprocessados, como pudins, gelatinas e doces em barra. Quanto à presença de frutas regionais, as regiões variaram pouco em sua oferta. Conclusão: Cada região deve adequar os cardápios planejados para os restaurantes universitários em diferentes aspectos, sendo essencial considerar questões nutricionais e sensoriais ao elaborá-los. 
Palavras-chave: Serviços de Alimentação. Universidades. Promoção da Saúde. Guias Alimentares. Planejamento de Cardápio.

\section{Abstract}

Objective: Measure the nutritional quality of planned menus for the university restaurants of Federal Universities in Brazil. Methods: A cross-sectional quantitative study which sample consists of 22 university restaurant menus, divided into their respective regions, prepared for lunch during the month of March 2015. For the analysis, we used the method of Qualitative Evaluation of Menu Components - QEMC, the Brazilian Food Guide, and the publication of the Ministry of Health on Food Regional Brazilian. Results and Discussion: Already colors of monotony and foods rich in sulfur had inadequate percentages, prompting an alert as colorful menus become more visually appealing and consumption of sulfur-rich meals can cause abdominal discomfort. The offer of vegetarian protein in the South and Southeast regions occurred in $50 \%$ and $88 \%$ of the analyzed menus, respectively. Regarding the presence of brown rice, $83 \%$ of the menus in the southern region and $78 \%$ of the menus in the southeast region planned supply. It is worth mentioning that the planning of the two items was less frequent or not offered by the Central-West, North and Northeast regions. Most of the restaurants offers ultra-processed candies, such as puddings, jellies and candy bars. For the presence of regional fruits, regions varied a little in their offer. Conclusion: Each region should tailor the planned menus to the college restaurants in different aspects, it is essential to consider nutritional and sensory questions to elaborate them.

Keywords: Food Services. Universities. Food Guide. Health Promotion. Menu Planning. 


\section{Introdução}

A alimentação está envolta nos mais diversos significados por abranger questões biológicas, psicológicas, sociais, culturais, econômicas e religiosas, que perfazem a vida do indivíduo. ${ }^{1}$

Nas últimas décadas, a mudança no estilo de vida e nos padrões de consumo alimentar está relacionada ao aumento na incidência de Doenças Crônicas Não Transmissíveis (DCNT), como obesidade, diabetes, hipertensão, entre outras. ${ }^{2}$ Tais mudanças referem-se à ingestão de alimentos com alta densidade energética, gordura saturada, carboidratos refinados, e baixa ingestão de fibras, frutas e hortaliças. ${ }^{3}$

Devido à menor disponibilidade de tempo para preparar e consumir os alimentos, atualmente observa-se cada vez mais a realização de refeições fora do ambiente domiciliar. ${ }^{4}$ Diante disso, as Unidades de Alimentação e Nutrição (UAN) devem ter como objetivo o fornecimento de refeições de qualidade, adequadas do ponto de vista nutricional, sensorial, higiênico sanitário, e que atendam ao perfil dos seus clientes. ${ }^{5} \mathrm{O}$ Brasil conta com uma série de políticas públicas que promovem refeições gratuitas ou subsidiadas, que incentivam a oferta de refeições saudáveis em espaços institucionais. Entre elas está a política de restaurantes universitários, parte do Plano Nacional de Assistência Estudantil.

Foi na década de 1950, quando a Universidade do Brasil, no Rio de Janeiro, disponibilizava restaurantes em algumas escolas e faculdades para atendimento de funcionários e estudantes, que foi criado o primeiro restaurante universitário. ${ }^{6}$

Para grande parte dos estudantes, o ingresso na universidade é marcado por intensas transformações. É o momento em que eles terão que se responsabilizar pela moradia, alimentação, finanças e estudos. $8^{7}$ Contudo, a dificuldade para conciliar essas tarefas pode influenciar no comportamento alimentar, resultando em práticas que futuramente podem trazer riscos à saúde. $9^{8}$

A existência do restaurante universitário pode minimizar o impacto que a mudança do domicílio familiar acarreta e contribuir para a manutenção da saúde do indivíduo, com a oferta de cardápios diversificados e nutritivos. $10^{9}$

Sabe-se que o ato de comer diz respeito à combinação das sensações olfativas, táteis, térmicas e auditivas. Sendo assim, uma refeição adequada apenas em quantidade e qualidade nutricional, desconsiderando os aspectos sensoriais, geralmente, não desperta nas pessoas interesse em consumila, uma vez que o indivíduo ingere alimentos e não nutrientes.11-13 10-12

As refeições oferecidas possibilitam aos estudantes condições fisiológicas necessárias ao desempenho das atividades. Logo, o restaurante universitário é considerado importante espaço promotor de educação alimentar e nutricional, já que o estímulo à adoção de hábitos alimentares saudáveis contribui para mudanças comportamentais. ${ }^{14}$ 
Portanto, o objetivo do estudo foi avaliar a qualidade nutricional dos cardápios planejados para restaurantes universitários das universidades federais no Brasil. De modo que os resultados possam subsidiar a elaboração de ações interventivas que visem a sua melhoria e, com isso, a satisfação dos clientes.

\section{Material e Métodos}

Trata-se de um estudo transversal quantitativo, cuja amostra consiste em cardápios planejados para os restaurantes universitários de 22 universidades federais, que representam 44,89\% das instituições que possuem o restaurante instalado no país.

Os cardápios foram divididos entre as regiões na qual a universidade estava localizada, sendo: região Sul $(n=6)$, Sudeste $(n=9)$, Centro-oeste $(n=1)$, Norte $(n=3)$ e Nordeste $(n=3)$.

Foi avaliado o cardápio mensal de cada universidade, planejado para o almoço de 22 dias úteis, segunda à sexta-feira, durante o mês de março de 2015. A análise do cardápio referente a um mês completo ocorreu para controlar o erro aleatório da medida dietética, que poderia decorrer da presença de um dia não característico do padrão de planejamento do cardápio.

\section{Coleta dos dados}

Para a seleção da amostra, realizou-se primeiramente uma análise prévia on-line do número de universidades federais em funcionamento, e foram identificadas 57 instituições, das quais 49 apresentavam o restaurante universitário em funcionamento.

Após esse momento, foi feito o primeiro contato via e-mail com os responsáveis pelos restaurantes a fim de apresentar a pesquisa, solicitar o cardápio de março de 2015 e a resposta de cinco perguntas elaboradas com o intuito de identificar o perfil do restaurante.

Tais perguntas eram relacionadas à diferença de cardápios entre os campi da universidade, número de refeições fornecidas no almoço em cada campus, valor da refeição (almoço), profissional responsável pela elaboração dos cardápios, e o tempo de existência do RU no campus.

Além disso, foi encaminhado o Termo de Consentimento Livre e Esclarecido (TCLE), para resguardar os direitos das instituições participantes, que deveria ser assinado e encaminhado ao pesquisador.

Após o recebimento, os cardápios passavam por uma avaliação inicial, para verificar possíveis ausências de informações que seriam relevantes durante as análises. 
Quando a universidade não respondeu ao primeiro e-mail, foi feito mais dois contatos com setores relacionados ao restaurante universitário, como a secretaria de assuntos estudantis.

Nesse caso, a amostra foi definida por conveniência, apenas participariam da pesquisa as instituições que atendessem em sua totalidade às solicitações feitas por e-mail.

Quando a instituição possuía diferentes cardápios entre os campi, priorizou-se coletar o cardápio elaborado para o restaurante do campus sede da universidade.

\section{Procedimentos para análise dos cardápios}

\section{Avaliação Qualitativa das Preparações do Cardápio (AQPC)}

Através do método da Avaliação Qualitativa das Preparações do Cardápio (AQPC) desenvolvido por Veiros, ${ }^{15}$ avaliaram-se os seguintes critérios: presença de frutas in natura como sobremesa, folhosos, monotonia das cores, alimentos ricos em enxofre, carne gordurosa, frituras, doces, doces e frituras no mesmo dia e conservas.

O cardápio apresentou monotonia de cores quando duas preparações de cor semelhante ou apenas a repetição de duas cores no cardápio estavam presentes. ${ }^{6,7} \mathrm{E}$ ricos em enxofre, considerouse quando havia duas ou mais preparações com um dos seguintes alimentos: acelga, aipo, batatadoce, brócolis, couve-de-bruxelas, couve-flor, ervilha, lentilha, nabo, ovo, rabanete, repolho, alho, cebola, abacate, amendoim, castanha, nozes, gengibre, goiaba, jaca, melancia, maçã, melão, uva, milho e mostarda. ${ }^{11,16}$

Foi avaliada a oferta de carne gordurosa nos dias em que não teve fritura como técnica de preparo das carnes. As carnes gordurosas são aquelas em que a gordura excede $50 \%$ do total energético, como aba de filé, acém, contrafilé, capa de filé, costela, fraldinha, paleta, pescoço, picanha, ponta de agulha, linguiça, salsicha, chuleta, hambúrguer e feijoada. ${ }^{17,18}$

Analisou-se a presença de fritura isoladamente e quando associada à oferta de doces, servidos como sobremesas, como pudins, gelatinas, sagus e sorvetes.

A avaliação de cada critério foi feita por ocorrência diária, em seguida semanal, e por último mensal, sendo o resultado obtido em porcentagem, considerando o total de 22 dias. Em seguida, fez-se uma média dos resultados obtidos por região, em cada critério analisado.

A oferta de frutas e folhosos foi definida como itens de aspecto positivo, e a partir do porcentual eles foram classificados da seguinte forma: ótimo, $\geq 90 \%$; bom, $75 \%$ a $89 \%$; regular, de $50 \%$ a $74 \%$; ruim, de 25\% a 49\%; péssimo, <25\%. Já as preparações com alimentos ricos em enxofre, carne gordurosa, monotonia das cores, fritura, doce, doce e fritura no mesmo dia e conservas 
foram definidas como itens de aspectos negativos, e a partir do porcentual foram classificadas em: ótimo, $\leq 10 \%$; bom, de $11 \%$ a $25 \%$; regular, de $26 \%$ a $50 \%$; ruim, de $51 \%$ a $75 \%$; e péssimo, $>75 \%$. Critérios utilizados por Prado, Nicoletti \& Faria. ${ }^{19}$

\section{Avaliação pelo Guia Alimentar para a População Brasileira}

A segunda edição do Guia Alimentar para a População Brasileira ${ }^{13}$ recomenda, para uma alimentação saudável, compor as refeições por alimentos in natura ou minimamente processados e predominantemente por alimentos de origem vegetal; limitar o uso de alimentos processados; $\mathrm{e}$ evitar alimentos ultraprocessados devido ao seu alto teor de sódio e açúcar. Por isso, verificou-se nos cardápios a presença de arroz integral, prato proteico vegetariano e o tipo de doces planejados nas sobremesas.

Para a análise da presença de arroz integral e prato proteico vegetariano, calculou-se a porcentagem considerando o número de restaurantes que planejam esse componente no cardápio em relação ao número total de restaurantes em cada região. Já a análise para o tipo de doces nas sobremesas, fez-se um levantamento do número de restaurantes que planejam essas preparações como sobremesa. Em seguida, calculou-se a distribuição em porcentagem, de acordo com o grau de processamento (doces ultraprocessados, doces à base de frutas e doces à base de frutas e ultraprocessados).

\section{Avaliação pela presença de alimentos regionais brasileiros}

Observou-se pelo livro Alimentos Regionais Brasileiros, elaborado pelo Ministério da Saúde, ${ }^{20}$ as frutas regionais planejadas para oferta in natura como sobremesa nos cardápios de todos os restaurantes em suas respectivas regiões.

Tal referência traz como frutas típicas da região Sul a amora, banana, feijoa, figo, maçã, morango, nectarina, pêssego, pinhão, tangerina/bergamota e uva.

Para os cardápios da região Sudeste, observou-se a presença de abacate, brejaúva, caqui, carambola, goiaba, jabuticaba, jaca, jambolão, laranja, manga, pinha, sapucaia e sapoti.

Na região Centro-oeste, abacaxi-do-cerrado, araticum, baru, cagaita, cajuí, coco-babão, cococabeçudo, coco-indaiá, coroa-de-frade, curriola, guabiroba, guapeva, jaracatiá, jatobá, jenipapo, lobeira, macaúba, mama-cadela, maracujá, marmelada-de-cachorro, pequi, pera-do-cerrado, pitanga, e xixá. 
As frutas típicas observadas na região Norte são: abricó, abiu, açaí, araçá, bacaba, bacuri, banana-pacova, biribá, buriti, cajarana, camu-camu, castanha-do-brasil/castanha-do-pará/castanhada-amazônia, cubiu, cupuaçu, cupuí, cutite, guaraná, inajá, ingá, jambo, mangaba, murici, piquiá, sumário, pupunha, sapota-do-solimões, sorva, taperebá, tucumã, umari e uxi.

As frutas regionais do Nordeste são: acerola, banana-nanica, banana-da-terra, cacau, cajá, cajarana, ciriguela, coco, dendê, fruta-pão, graviola, juá, mamão, maracujá, pitomba, sapoti, tamarindo e umbu.

Vale ressaltar que a oferta das referidas frutas pelos restaurantes universitários dependem de questões que permeiam a sazonalidade, o custo, bem como sua aplicabilidade em uma UAN. A análise foi feita considerando a totalidade de cardápios de cada região em relação aos dias em que houve o planejamento de frutas típicas.

\section{Análise estatística}

Os dados foram tabulados pelo programa Microsoft Excel@ 2010, e para a análise estatística, utilizou-se medidas descritivas e tabelas de frequência.

Para comparar as regiões quanto aos critérios do método AQPC, empregou-se o modelo de variância com um fator fixo, e nesta etapa da análise não foi considerada a região Centro-oeste, pois teve apenas uma unidade amostral contemplada.

O Teste exato de Fisher foi usado para comparar as regiões quanto às recomendações do Guia Alimentar. ${ }^{21,22} \mathrm{O}$ nível de significância considerado para as análises foi de 0,05 .

\section{Aspectos éticos}

O projeto foi submetido ao Comitê de Ética em Pesquisa com Seres Humanos da Universidade Federal de São Paulo e aprovado sob o no 859.348, em 4 de novembro de 2014.

\section{Resultados e Discussão}

\section{Avaliação Qualitativa das Preparações do Cardápio - AQPC}

A Tabela 1 apresenta a média dos percentuais e o desvio-padrão (DP) obtidos nos critérios do método AQPC, segundo a amostra de cada região. 
Tabela 1. Medidas descritivas para os critérios do método Avaliação Qualitativa das Preparações do Cardápio - AQPC, segundo as regiões. Brasil, 2015.

\begin{tabular}{|c|c|c|c|c|c|c|c|c|c|c|}
\hline \multirow[b]{3}{*}{ Critérios } & \multicolumn{10}{|c|}{ Região } \\
\hline & \multicolumn{2}{|c|}{ Sul } & \multicolumn{2}{|c|}{ Sudeste } & \multicolumn{2}{|c|}{ Centro-oeste } & \multicolumn{2}{|c|}{ Norte } & \multicolumn{2}{|c|}{ Nordeste } \\
\hline & Média & DP & Média & DP & Média & DP & Média & DP & Média & DP \\
\hline Frutas & 65,15 & 31,45 & 77,78 & 33,05 & 100,0 & - & 50,0 & 12,03 & 81,82 & 27,65 \\
\hline Folhosos & 91,67 & 14,2 & 87,88 & 14,55 & 100,0 & - & 96,97 & 2,63 & 75,76 & 18,92 \\
\hline Monotonia das cores & 46,21 & 12,99 & 49,5 & 19,87 & 54,55 & - & 56,06 & 56,06 & 53,03 & 5,25 \\
\hline Ricos em enxofre & 34,09 & 14,87 & 42,93 & 15,1 & 63,64 & - & 34,85 & 18,92 & 63,64 & 15,75 \\
\hline Carne gordurosa & 15,91 & 10,66 & 19,7 & 18,3 & 22,73 & - & 18,18 & 47,44 & 16,67 & 13,1 \\
\hline Doces & 36,37 & 29,6 & 35,86 & 38,9 & 0,0 & - & 50,0 & 12,0 & 83,33 & 28,9 \\
\hline Frituras & 19,7 & 10,6 & 19,19 & 21,1 & 50,0 & - & 19,7 & 6,94 & 25,76 & 6,94 \\
\hline Doces e Frituras & 14,4 & 12,67 & 15,66 & 29,56 & 0,0 & - & 19,7 & 9,46 & 30,3 & 6,94 \\
\hline Conservas & 4,55 & 4,98 & 15,66 & 10,69 & 9,09 & - & 9,09 & & 15,15 & 5,45 \\
\hline
\end{tabular}

Nota-se que as regiões com maior média para a oferta de frutas nos cardápios foram a Sudeste (77,78\%), Centro-oeste (100\%) e Nordeste $(81,82 \%)$. Já as regiões Sul $(65,15 \%)$ e Norte $(50,00 \%)$ possuem médias classificadas como regulares. A presença de folhosos nas saladas, por sua vez, foi adequada para todas as regiões, e o desvio-padrão da região Nordeste $(18,92)$ sugere que houve grande variação de oferta na respectiva amostra.

Ofertar diariamente frutas e hortaliças nos cardápios é essencial para a composição de uma alimentação equilibrada, pois são alimentos fontes de vitaminas, minerais, antioxidantes e fibras, associados a diversos efeitos benéficos para a saúde. ${ }^{23-25}$

A alimentação de 120 universitários com idade média de 22 anos no município de São Paulo foi avaliada pelo Questionário de Frequência Alimentar (QFA) e observou-se que menos da metade dos estudantes $(44,16 \%)$ consumiam frutas menos de cinco dias na semana, reforçando a importância da oferta destes alimentos no local de estudo. ${ }^{26}$

Cattafesta e colaboradores (2014) conduziram uma pesquisa com 208 universitários públicos federais e mostraram que o almoço realizado no RU era a principal refeição do dia para $76 \%$ dos estudantes, e 86,1\% deles relataram utilizar o RU pelo menos três vezes por semana, ${ }^{27}$ Esse dado sugere que as refeições fornecidas nesses estabelecimentos possuem potencial para promoção da saúde e formação de hábitos alimentares, já que o contato diário com frutas, hortaliças e leguminosas incentivam seu consumo. 
Em relação ao critério monotonia das cores, observou-se que não houve bons porcentuais para nenhuma região, sendo prevalente a cor branca com amarelo claro, por exemplo, planejar em um mesmo cardápio ovo cozido como prato proteico, batata sautée na guarnição, melão de sobremesa e suco de limão para bebida. O estudo realizado em uma UAN em Belo Horizonte, Minas Gerais, teve resultado semelhante para o item, $69 \%$ dos dias com cardápios monótonos em suas cores. ${ }^{28}$

A diversidade de cores contribui para a apresentação visual do cardápio, o que interfere nas escolhas alimentares e satisfação dos comensais. Além disso, um prato colorido indica maior variedade de vitaminas. ${ }^{29}$

Outro critério avaliado pelo AQPC foi a presença de alimentos ricos em enxofre, exceto o feijão, por ser um alimento típico do brasileiro. Observou-se que as cinco regiões não apresentaram médias de oferta adequadas, com destaque ao Centro-oeste e Nordeste, que se classificaram como ruins, $63,64 \%$. Observou-se também que os alimentos sulfurados foram empregados principalmente nas saladas, e os mais comuns foram a acelga e o repolho, devido, provavelmente, ao menor fator de correção e, consequentemente, melhor rendimento e custo. ${ }^{30}$

Um estudo realizado no município de São Paulo avaliou o almoço oferecido por uma organização não governamental para pacientes oncológicos e identificou que 43, \% dos dias ofereciam alimentos ricos em enxofre, sendo que o consumo excessivo em uma mesma refeição pode causar desconforto abdominal e produção de flatos. ${ }^{5,17}$

Vale ressaltar a necessidade de atenção durante a elaboração dos cardápios para a monotonia de cores e excesso de compostos sulfurados, visto que, para grande parte dos universitários, o almoço ofertado pelo RU é a sua principal refeição do dia.

O planejamento de carne gordurosa indicou bons porcentuais de adequação para todas as regiões, sendo as médias de oferta inferiores a $25 \%$ dos dias avaliados.

Estudos realizados em UAN institucionais, a fim de avaliar a presença de carne gordurosa, encontraram porcentuais superiores ao da presente análise, 37,5\%, 52,4\% e 70,58\% dos dias avaliados, respectivamente. ${ }^{1,28,31}$ Enquanto outra análise feita também nesse tipo de estabelecimento observou a oferta em apenas $7 \%$ do período. ${ }^{5}$

As principais carnes gordurosas verificadas nos cardápios foram o acém, contrafilé, costela, linguiça toscana, calabresa, e preparações como feijoadas e dobradinhas.

Apesar das carnes processadas apresentarem praticidade, baixo custo e boa aceitação pelos comensais, estudos demonstram que o consumo está associado ao risco de câncer colorretal, devido à presença de compostos nitrosos. ${ }^{32}$

Observou-se também que alguns restaurantes utilizam ingredientes como creme de leite, maionese, bacon, presunto, queijo mussarela e batata palha. Tendo em vista que sua utilização 
aumenta o valor calórico das preparações, é importante avaliar o uso e a necessidade desses ingredientes para a receita.

Quanto à presença de doces como sobremesa, verifica-se que apenas a região Centro-oeste não ofertou doces no período do estudo e sim, frutas in natura. A região Nordeste indicou a maior frequência de oferta, em média, 83,33\% dos dias avaliados, contudo, disponibilizou frutas in natura como opção aos estudantes. As regiões Norte (50\%), Sul (36,37\%), e Sudeste (35,86\%) apresentaram porcentuais médios classificados como regulares, e nesses dias não ofereceram a fruta in natura como opção.

Dois estudos mostraram resultados semelhantes ao obtido pela região Nordeste, sendo a oferta em $66,6 \%$ e $88,2 \%$ do período, respectivamente. ${ }^{3,31}$

De acordo com o Guia Alimentar para População Brasileira,${ }^{13}$ óleos, gorduras e açúcar têm elevada quantidade de calorias por grama, sendo que o açúcar tem cinco a dez vezes mais calorias por grama que a maioria das frutas.

O único cardápio analisado da região Centro-oeste apresentou elevado teor calórico, pois se verificou o emprego de frituras por imersão em $50 \%$ dos dias, assim como observado por outras analises cujos porcentuais foram de 49,5\% e 50,9\%, respectivamente. ${ }^{17,27}$ As demais regiões do presente estudo tiveram índices inferiores a 25\%, o que demonstra preocupação com a escolha das técnicas de cocção.

Geralmente, a fritura é escolhida por conferir aspectos sensoriais agradáveis e ser rápida, otimizando o tempo de preparo quando alguma mudança for necessária. Essa técnica de cocção foi empregada principalmente nos pratos proteicos, quando comparado ao emprego nas guarnições, como observado em estudo semelhante. ${ }^{1}$

Para evitar o emprego de óleo nas preparações, o restaurante pode utilizar métodos de cocção de ar quente, por meio de fornos combinados. ${ }^{33}$ Segundo Araújo,${ }^{34}$ a utilização de gorduras em alguns métodos é necessária, porém, na maioria, o uso pode ser reduzido ou eliminado, utilizando apenas ar quente.

A associação de alimentos fritos com doces esteve adequada para as regiões Sul (14,4\%), Sudeste $(15,6 \%)$ e Norte (19,7\%). A região Nordeste demonstrou maior frequência, em 30,3\% dos dias analisados, e o desvio-padrão de 6,94 sugere que houve pouca variação entre os restaurantes da região.

Tal como em nosso estudo, outra pesquisa feita em uma UAN localizada na cidade de Belo Horizonte, Minas Gerais, mostrou semelhança ao resultado obtido, 35,7\%.28

O último critério avaliado foi a presença de conservas nos cardápios, que mostrou níveis excelentes de adequação para todas as regiões, inferior a 16, \%, sendo identificado maior presença desses alimentos nas saladas. 
O estudo descritivo realizado em uma UAN na cidade de Vitória, Espirito Santo, observou que as conservas eram utilizadas em pequenas quantidades, porém em guarnições e pratos proteicos, com o objetivo de decorar ou finalizar preparações. ${ }^{31}$

Limitar o consumo de alimentos processados, como as conservas, é necessário devido à grande quantidade de sódio, usado para dar sabor e controlar o crescimento de microrganismos. A ingestão de cloreto de sódio em excesso aumenta a pressão sanguínea e o risco para doenças do coração. ${ }^{13,35}$

Entre os critérios do método AQPC, folhosos, carne gordurosa e conservas apresentaram-se apropriados para todas as regiões, enquanto monotonia das cores e alimentos ricos em enxofre tiveram médias regulares ou inadequadas.

Pode-se inferir, de forma geral, que a região Sudeste esteve mais adequada pelo método, porém não houve diferença estatística significativa entre as regiões $(\mathrm{p}<0,05)$.

\section{Guia Alimentar para a População Brasileira}

Com relação ao planejamento de prato proteico vegetariano e arroz integral, verificou-se que dos cardápios avaliados das regiões Sul, Sudeste e Centro-oeste, 50\%, 88\% e 100\%, respectivamente, consideraram o item para oferta aos estudantes. Já nas regiões Norte e Nordeste, em média, 33\% dos cardápios planejaram ofertar essa preparação. Vale ressaltar que na região Centro-oeste foi avaliado o cardápio de apenas uma universidade. Através do teste estatístico, é possível inferir que houve diferença significativa para a oferta de arroz integral entre as regiões $(p=0,006)$.

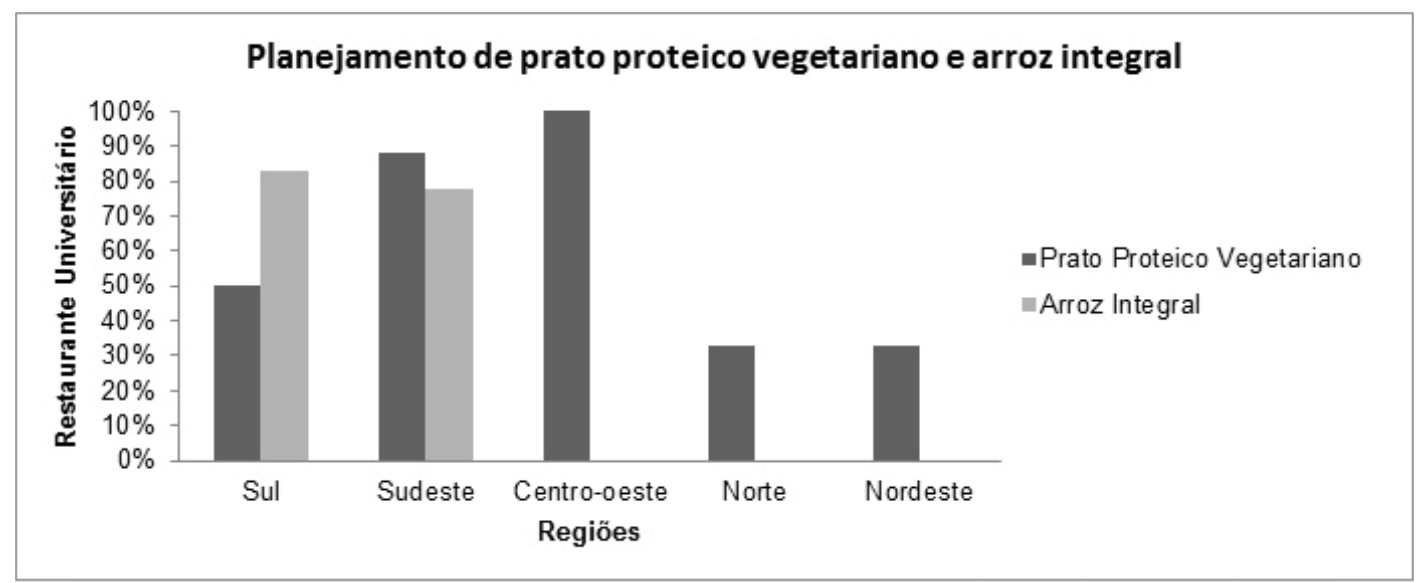

Para comparar as regiões quanto às variáveis categóricas, utilizou-se o teste exato de Fisher, e os resultados permitem inferir que há diferença significativa para a oferta de arroz integral, $\mathrm{p}<0,05$.

Figura 1. Planejamento de prato proteico vegetariano e arroz integral nos restaurantes universitários, segundo as regiões. 
Os alimentos de origem animal são considerados boas fontes de proteínas, vitaminas e minerais, mas não contêm fibras e ainda podem apresentar grande quantidade de calorias por meio das gorduras saturadas, que em excesso favorecem o risco de obesidade, doenças cardiovasculares, entre outras. Já os alimentos de origem vegetal costumam ser fontes de fibras, de vários nutrientes e geralmente são menos calóricos. ${ }^{13}$

Um estudo que analisou o risco cardiovascular de vegetarianos e onívoros mostrou que a pressão arterial, glicemia de jejum, colesterol total, LDL-colesterol e triglicerídeos foram mais baixos entre vegetarianos. ${ }^{36}$

Dietas vegetarianas restritivas ou desequilibradas podem causar deficiências nutricionais, em especial, nas situações de demanda metabólica aumentada, porém, quando são feitas de maneira equilibrada, trazem benefícios à saúde. ${ }^{37}$

Com relação à presença de arroz integral, verificou-se que 83\% dos cardápios da região Sul e $78 \%$ da região Sudeste ofertaram diariamente esse componente no período analisado, enquanto as regiões Centro-oeste, Norte e Nordeste não disponibilizaram esse alimento como opção aos estudantes.

Entre os motivos que podem justificar a ausência desse alimento nos cardápios estão o custo, por ser mais alto quando comparado ao arroz polido, o habito alimentar da região e a falta de maior detalhamento das refeições no edital do restaurante universitário para a empresa terceirizada.

Segundo o Guia Alimentar, ${ }^{13}$ em algumas situações, as técnicas de processamento mínimo, como o polimento excessivo de grãos, podem reduzir a quantidade de nutrientes dos alimentos. Nesses casos, deve-se preferir o alimento menos processado, como a farinha de trigo menos refinada e o arroz integral.

Através da análise dos tipos de doces mais comuns nas sobremesas, averigou-se que do total de cardápios que oferta essa preparação $(n=19), 79 \%(n=15)$ disponibilizam doces ultraprocessados, como pudins, gelatinas e doces em barra, $16 \%(n=3)$ oferecem sobremesas elaboradas à base de frutas in natura e 5\%, o equivalente ao cardápio de uma universidade, intercalou entre a oferta de doces ultraprocessados e feitos com a fruta in natura.

Sabe-se que o alto consumo de produtos ultraprocessados está relacionado com uma menor qualidade global da alimentação, além de associar-se ao excesso de peso e surgimento de DCNT. ${ }^{38}$

O fato de as universidades optarem por doces do tipo ultraprocessados em vez de doces elaborados com a fruta in natura pode estar relacionado com fatores como custo, praticidade, aceitação dos universitários, bem como armazenamento e durabilidade. ${ }^{39}$ 


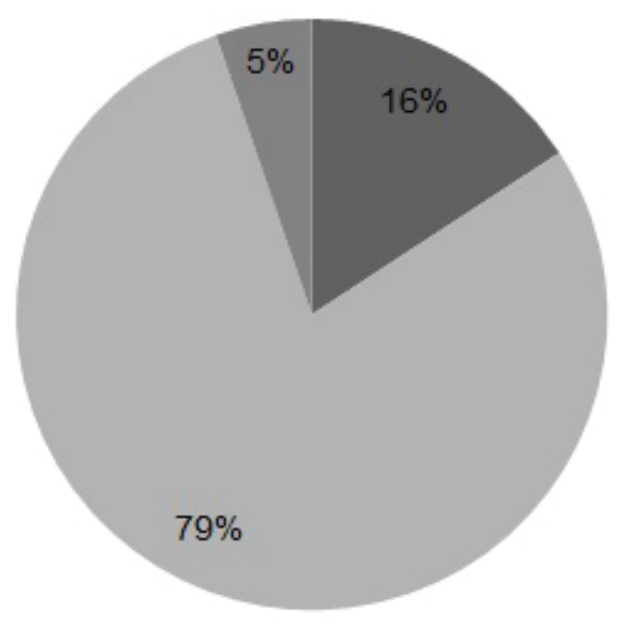

- À base de alimentos in natura

-Ultraprocessados

$\square$ À base de alimentos in natura e Ultraprocessados

Figura 2. Distribuição dos tipos de doces planejados nos cardápios.

Uma pesquisa realizada na Universidade de Brasília avaliou as opções de alimentos disponibilizados em 29 pontos de vendas de alimentos e verificou que os itens mais frequentes foram bebidas prontas para consumo, refrigerantes, chocolates, balas e chicletes. E quanto aos motivos relatados para a venda desses produtos, a maioria $(n=19)$ relatou ser pela praticidade de preparo e venda, a demanda dos estudantes, o baixo custo, serem produtos saborosos e lucrativos. ${ }^{40}$

Ainda com base no mesmo estudo, observou-se que, apesar das hortaliças frescas estarem presentes em $62 \%(n=18)$ dos estabelecimentos avaliados, na maioria das vezes a oferta era feita em pequenas porções que acompanhavam opções não saudáveis, como hambúrgueres. ${ }^{40}$

No presente estudo, notou-se que apenas seis cardápios disponibilizam a fruta in natura como opção aos estudantes, quando há oferta de doces nas sobremesas. Um estudo realizado com estudantes universitários mostrou baixa frequência de consumo diário de alimentos, como feijão, hortaliças e frutas, com destaque aos estudantes que relataram ingerir esses alimentos somente um ou dois dias na semana. Em contrapartida, os resultados observaram maior recorrência para o consumo diário de bebidas açucaradas (46,2\%), guloseimas (24,9\%) e biscoitos e/ou salgadinhos industrializados $(17,9 \%) .{ }^{41}$ 
Os alimentos ultraprocessados são formulações industriais, cujos ingredientes fazem com que eles sejam ricos em gorduras e/ou açúcares e apresentem alto teor de sódio. Além disso, esses produtos possuem baixo teor de fibras, vitaminas e minerais, devido à ausência ou limitada presença de alimentos in natura ou minimamente processados. Embora cada aditivo utilizado durante o ultraprocessamento seja testado e aprovado por autoridades sanitárias, os efeitos em longo prazo sobre a saúde são desconhecidos. ${ }^{13}$

Os resultados obtidos após a análise estatística permitem afirmar que as regiões tendem a diferir com relação à oferta de arroz integral $(\mathrm{p}<0,05)$, contudo, o tamanho da amostra não é suficiente para uma desejável precisão nos resultados.

\section{Alimentos Regionais Brasileiros}

A culinária do Brasil incorpora a cultura de diferentes populações, como a indígena, africana, portuguesa, entre outras. Alguns alimentos são bem conhecidos, como a mandioca e a goiaba, porém, muitos vêm sendo esquecidos com o passar dos anos devido ao processo de urbanização. ${ }^{42}$

Promover alimentação saudável significa também escolher alimentos relacionados à cultura local, de forma a estimular a cozinha típica regional e assim contribuir para o resgate de tradições. ${ }^{20}$

A alimentação é um símbolo de identidade para o homem, e para além de se referir aos hábitos e comportamentos alimentares, ela serve para nutrir o corpo e demonstrar pertencimento social. ${ }^{43}$ Nesse sentido, a herança alimentar envolve múltiplos aspectos, e o presente trabalho se ateve apenas a avaliar um deles, que é a oferta de frutas típicas da região, tendo em vista a importância de se valorizar os alimentos regionais e contribuir para o desenvolvimento local.

A observação do planejamento de frutas regionais como sobremesas nos cardápios permitiu inferir que as regiões variaram pouco em sua oferta. E apesar de algumas questões inviabilizarem a oferta pelos restaurantes, como dificuldade para compor o cardápio de uma UAN com grande número de comensais, praticidade, custo e sazonalidade, esse fato chama a atenção devido à riqueza e versatilidade que cada região possui na produção de alimentos.

Os cardápios da região Norte, por exemplo, não apresentaram frutas típicas como sobremesa no período analisado. Na região Sul, verificou-se nos cardápios o planejamento de banana, maçã e pêssego. Quanto à presença de frutas típicas in natura nos cardápios da região Sudeste, obtevese laranja, goiaba e manga, sendo a laranja mais empregada nos cardápios quando comparada às demais.

Como frutas regionais do Nordeste, observou-se apenas banana-nanica e mamão nos cardápios universitários. A região Centro-oeste, por conter apenas uma unidade amostral, não foi analisada para o critério. 
Vale ressaltar que o presente estudo analisou o cardápio planejado para os restaurantes universitários e não a real oferta das preparações em cada um deles.

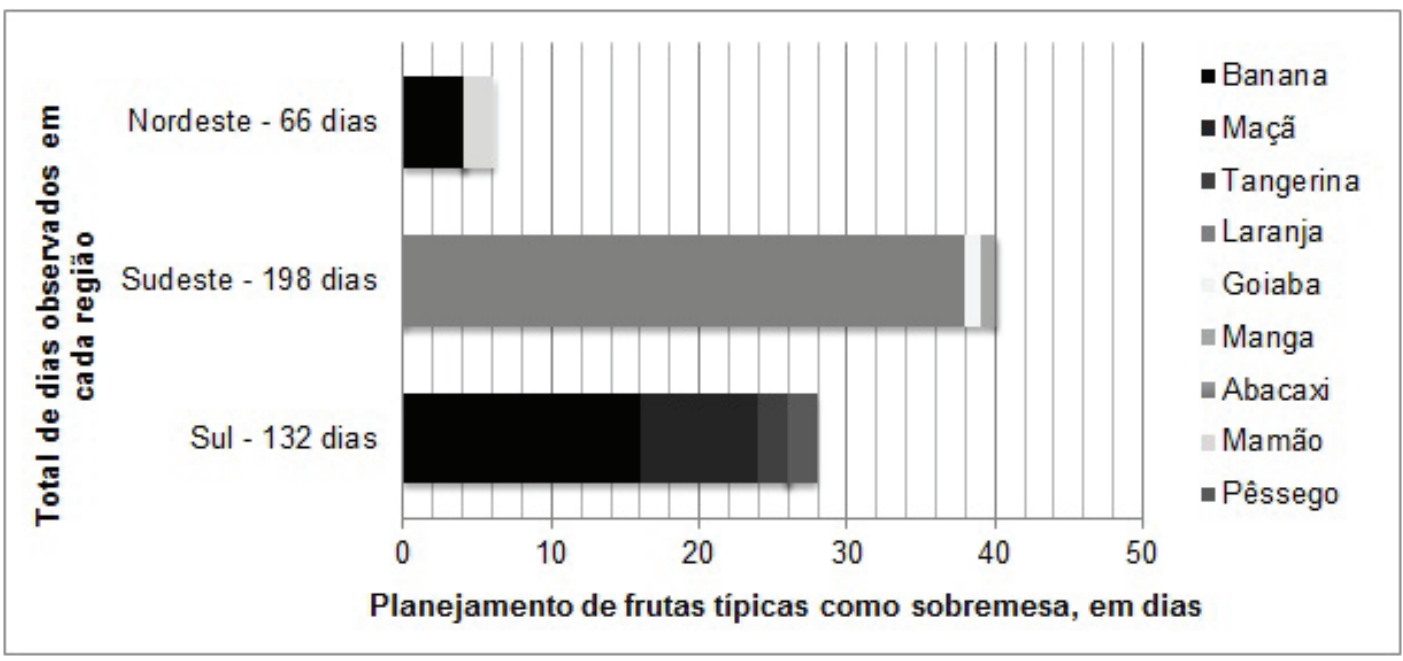

Figura 3. Planejamento de frutas regionais nos cardápios, segundo o número de dias observados em cada região.

\section{Conclusão}

Embora a oferta de folhosos, carne gordurosa e conservas ter se mostrado adequada, os cardápios apresentaram médias regulares ou inadequadas em diferentes aspectos, em especial, para a oferta de alimentos ricos em enxofre e monotonia das cores.

Com relação à oferta de prato proteico vegetariano e arroz integral, as-regiões Centro-oeste, Norte e Nordeste apresentaram baixa oferta desses componentes nos cardápios quando comparado às demais regiões.

Faz-se necessário reduzir a oferta de doces ultraprocessados, procurando valorizar a fruta in natura regional nas sobremesas, de modo a incentivar a produção local, bem como a oferta de itens essenciais ao cardápio.

Além disso, durante a elaboração dos cardápios é importante considerar os aspectos nutricionais e sensoriais, priorizando alimentos in natura e minimamente processados, visto que as refeições oferecidas aos estudantes são veículos de promoção da alimentação adequada e saudável. 


\section{Colaboradores}

Benvindo JLS participou do desenho do estudo; realizou a coleta, a análise e a interpretação dos dados; redigiu o artigo e a sua versão final. Pinto AMS orientou todas as etapas do estudo, desde a sua concepção até a revisão da versão final do artigo. Bandoni DH orientou a escrita e revisão da versão do artigo.

\section{Referências}

1. Passos, ALA. Análise do cardápio de uma unidade de alimentação e nutrição institucional em Brasília - DF segundo o método "Avaliação Qualitativa das Preparações do Cardápio" [Monografia de especialização]. Brasília: Centro de Excelência em Turismo, Brasília: Universidade de Brasília, 2008.

2. Garcia RWD. Reflexos da globalização na cultura alimentar: considerações sobre as mudanças na alimentação urbana. Rev. Nutr. 2003; 16(4):483-492.

3. Pereira JP, Bello PD, Locatelli NT, Pinto MAS, Bandoni DH. Qualidade das refeições oferecidas por empresas cadastradas pelo Programa de Alimentação do Trabalhador na cidade de Santos-SP. O Mundo da Saúde 2014; 38(3):325-333.

4. Rosso TF. Avaliação da Qualidade Nutricional e Sensorial (AQNS) de preparações servidas no almoço em um restaurante comercial da cidade de criciúma/SC. [Trabalho de conclusão de curso]. Criciúma: Universidade do Extremo Sul Catarinense, Curso de Nutrição; 2010.

5. Machado AD, Olivon EV, Matias ACG, Abreu ES. Avaliação do almoço oferecido a pacientes oncológicos e transplantados pediátricos pelo método AQPC. Rev Ciênc Méd Biol. 2013; 12(3):332-336.

6. Proença RPC. Considerações iniciais sobre alimentação e processamento de refeições. In: Proença RPC. Inovação tecnológica na produção de alimentação coletiva. $3^{a}$ ed. Florianópolis: Insular; 2009.

7. Proença RPC. Alimentação coletiva no Brasil. In: Proença RPC. Inovação tecnológica na produção de alimentação coletiva. $3^{a}$ ed. Florianópolis: Insular; 2009.

8. Almeida ABP, Amorim ALB, Pinto MAS, Bandoni DH, Avaliação do comportamento alimentar de estudantes universitários. 12o Congresso Nacional da SBAN. Nutrite 2013; 38(Supl.):411.

9. Fausto MA, Ansaloni JÁ, Silva ME, Garcia Júnior J, Dehn AA, César TB. Determinação do perfil dos usuários e da composição química e nutricional da alimentação oferecida no restaurante universitário da universidade estadual paulista, Araraquara, Brasil. Rev. Nutr. 2001; 14(3):171-176.

10. Oliveira RB, Guaglianoni DG, Demonte A. Perfil do usuário, composição e adequação nutricional do cardápio oferecido em um restaurante universitário. Alim Nutr. 2005; 16(4):397-401.

11. Proença RPC, Hering B, Sousa AA, Veiros MB. Qualidade nutricional e sensorial na produção de refeições. Florianópolis: UFSC; 2005. 221 p.

12. Ornellas LH. A Alimentação através dos tempos. 2 ed. Florianópolis: Ed. UFSC, 2000. 306 p.

13. Brasil. Ministério da Saúde. Secretaria de Atenção à Saúde. Departamento de Atenção Básica. Guia alimentar para a população brasileira. 2. ed. Brasília: Ministério da Saúde; 2014. 156 p. 
14. Gorgulho BM, Lipi M, Marchioni DML. Qualidade nutricional das refeições servidas em uma unidade de alimentação e nutrição de uma indústria da região metropolitana de São Paulo. Rev Nutr. 2011; 24(3):463-472.

15. Veiros MB. Análise das condições de trabalho do nutricionista na atuação como promotor de saúde em uma Unidade de Alimentação e Nutrição: um estudo de caso [Dissertação]. [Santa Catarina]: Universidade Federal de Santa Catarina; 2002.

16. Reis NT. Nutrição clínica: sistema digestório. Rio de Janeiro: Rubio; 2003. 294 p.

17. Veiros MB, Proença RPC. Avaliação qualitativa das preparações do cardápio em uma unidade de alimentação e nutrição: método AQPC. Rev. Nutrição em Pauta 2003; 13(74):1-7.

18. Philippi ST. Nutrição e técnica dietética. 2. ed. Barueri: Manole; 2008. 402 p.

19. Prado BG, Nicoletti AL, Farias CS. Avaliação qualitativa das preparações de cardápio em uma unidade de alimentação e nutrição de Cuiabá- MT. UNOPAR Cient Ciênc Biol Saúde 2013; 15(3):219-23.

20. Brasil. Ministério da Saúde. Secretaria de Atenção à Saúde. Departamento de Atenção Básica. Alimentos regionais. 2. ed. Brasília: Ministério da Saúde; 2015. 484 p.

21. Eves A, Kipps M, Parlett G. Undernourished students: myth or reality? Nutrition and Food Science 1995; (2):5-11.

22. Agresti A. An introduction to categorical data analysis. 2 ed. New York: Wiley-Interscience; 2002.

23. Fagundes ALN, Ribeiro DC, Naspitz L, Garbelini LEB, Vieira JKP, Silva AP, et al. Prevalência de sobrepeso e obesidade em escolares da região de Parelheiros do município de São Paulo. Rev Paul Pediatr. 2008; 26(3): 212-217.

24. Steemburgo T, Dall'Alba V, Gross JL, Azevedo MJ. Fatores dietéticos e síndrome metabólica. Arq Bras Endocrinol Metab. 2007; 51(9):1425-1433.

25. Ramalho IR, Henriques EMV, Mara E. Consumo alimentar de crianças atendidas em ambulatório de nutrição de unidade de assistência secundária em Fortaleza - Ceará. Rev Bras Promoç Saúde 2009; 22(2):81-87.

26. Santos AKGV, Reis CC, Chaud DMA, Morimoto JM. Qualidade de vida e alimentação de estudantes universitários que moram na região central de São Paulo sem a presença dos pais ou responsáveis. Rev. Simbio-Logias 2014; 7(10):76-99.

27. Cattafesta M. Condições higiênico-sanitárias de um restaurante universitário e as práticas alimentares de seus usuários. Rev. Bras. Pesq. Saúde 2012; 14(4):36-43.

28. Ramos SA, Souza FFR, Fernandes GCB, Xavier SKP. Avaliação qualitativa do cardápio e pesquisa de satisfação em uma unidade de alimentação e nutrição. Alim. Nutr. Braz. J. Food Nutr. 2013; 24(1):29-35.

29. Veiros MB, Proença RPC, Kent-Smith L. Hering B, Sousa AA. How to analyse and develop healthy menus in foodservice. Journal of Foodservice. 2006; 17(4):159-165.

30. Lemos AG, Botelho RBA, Akutsu RCCA. Determinação do fator de correção das hortaliças folhosas comercializadas em Brasília. Horticultura Brasileira 2011; 29:231-236. 
31. São José JFBS. Avaliação qualitativa de cardápios em uma unidade de alimentação e nutrição localizada em Vitória-ES. Demetra; 2014; 9(4):975-984.

32. Zandonai AP, Sonobe HM, Sawada NO. Os fatores de riscos alimentares para câncer colorretal relacionado ao consumo de carnes. Rev Esc Enferm. USP 2012; 46(1):234-239.

33. Monteiro MAM, Calixto CFS, Azevedo JFM, Schaefer MA. Avaliação da quantidade de óleo de soja em refeições oferecidas em um restaurante universitário. Demetra 2013; 8(1):53-61.

34. Araújo VMC. Alquimia dos alimentos. 2. ed. Brasília: Senac; 2008.

35. Assis MAA. Consulta de nutrição: controle e prevenção do colesterol elevado. 2 ed. Florianópolis: Ed. UFSC; 2001. 166 p.

36. Teixeira RCMA, Molina MCB, Zandonade E, Mill JG. Risco cardiovascular em vegetarianos e onívoros: um estudo comparativo. Arq Bras Cardiol. 2007; 89(4):237-244.

37. Teixeira RCMA, Molina MCB, Flor DS, Zandonade E, Mill JG. Estado nutricional e estilo de vida em vegetarianos e onívoros - Grande Vitória - ES. Rev Bras Epidemiol. 2006; 9(1):131-43.

38. Moubarac JC, Martins APB, Claro RM, Levy RB, Cannon G, Monteiro CA. Consumption of ultraprocessed foods and likely impact on human health. Evidence from Canada. Public Health Nutr. 2012; 16(12):2240-2248.

39. Monteiro CA, Moubarac JC, Cannon G, Ng SW, Popkin B. Ultra-processed products are becoming dominant in the global food system. Obes Rev. 2013; 14:21-8

40. Neves LCM. Oferta de alimentos ultraprocessados na Universidade de Brasília. Brasília. [Trabalho de Conclusão de Curso]. [Brasília]: Universidade de Brasília; 2016.

41. Perez PMP, Castro IRR, Franco AS, Bandoni DH, Wolkoff DB. Práticas alimentares de estudantes cotistas e não cotistas de uma universidade pública brasileira. Ciênc Saúde Coletiva 2016; 21(2):531-542.

42. Rotenberg S, Marcolan S, Tavares EL, et al. Oficinas culinárias na promoção da saúde. In: DiezGarcia RW, Cervato-Mancuso AM, organizadores. Mudanças alimentares e educação nutricional. Rio de Janeiro: Guanabara Koogan; 2012. p. 327-334.

43. Maciel ME. Olhares antropológicos sobre a alimentação: identidade cultural e alimentação. In: Canesqui AM, Garcia RWD, organizadores. Antropologia e nutrição: um diálogo possível. Rio de Janeiro: Editora FIOCRUZ; 2005. p. 22-47. 